\title{
Bedform characteristics in a gravel-bed river
}

\author{
Hossein Afzalimehr ${ }^{1}$, Mohammad Reza Maddahi ${ }^{2}$, Jueyi Sui ${ }^{3 *}$ \\ ${ }^{1}$ Department of Civil Engineering, Iran University of Science and Technology, Tehran, Iran. \\ ${ }^{2}$ Department of Water Engineering, Shahid Bahonar University of Kerman, Kerman, Iran. \\ ${ }^{3}$ Environmental Engineering Program, University of Northern British Columbia, Prince George, BC, Canada. \\ ${ }^{*}$ Corresponding author. E-mail: Jueyi.sui@unbc.ca
}

\begin{abstract}
Estimation of hydraulic and geometric parameters of a gravel-bed river such as dimensions of bedforms is very difficult task, although they play a fundamental role in river engineering projects. One of the methods to get essential information regarding the bedform characteristics is to find the relations between the flow parameters and bedform dimensions. We conducted this field study in the Babolroud River in northern Iran to investigate the application of double averaged method in unspecific gravel bedforms to evaluate friction factor. Using data collected from several river reaches with total length of $356 \mathrm{~m}$ of a gravel-bed river, the relationship between bedform geometry (height and the length of bedforms) and flow parameters including shear velocity, transport stage parameter with friction factor is investigated. Different methods for estimating bedforms dimensions are examined to assess the ability of predicting bedform parameters (length and height) in a gravel-bed river. Using bedform parameters, the contribution of particle and form friction is estimated. Results confirm the application of the double averaged method and existing bedform parameters for unspecific bedforms. There exists a similar trend between aspect ratio and friction factor in gravel bedforms.
\end{abstract}

Keywords: Bedform characteristics; Gravel-bed river; Field measurements; Form friction factor.

\section{INTRODUCTION}

Rivers or river systems are very important sources for supplying fresh water and habitat of aquatic animals, play a vital role in human beings and livelihood. Recent studies show that bedforms are important features on fish habitat (e.g., Dey, 2014; Fazlollahi, 2015a and b). Also bedforms play a significant role on friction factor and sediment transport in rivers (Garcia, 2008; Julien, 2010). In the past half-century, a lot of attempts have been done to relate bedform and flow characteristics in alluvial channels (e.g., Carling, 1999; Carling et al., 2005; Formann et al., 2007; Keylock et al., 2014; Liedermann et al., 2014; MacVicar and Rennie, 2012; Milan, 2012; Singh et al., 2012; van der Mark et al., 2008). From the published research work including above-mentioned literature, some issues do need further investigation including the aspect ratio (the ratio of channel width $W$, to flow depth $h$ ). Up to date, the aspect ratio is normally not considered in the studies of bedforms of gravel-bed rivers. Bennett and Best (1995) did experiments in a laboratory flume with the width of $W=0.3 \mathrm{~m}$. In their experiments, the aspect ratio is $W / h=3$ and the median size of bed materials is $D_{50}=0.22 \mathrm{~mm}$. To investigate turbulent flow characteristics on bedforms, Singh et al. (2012) did experiments in a flume with the width of $2.75 \mathrm{~m}$ and length of $84 \mathrm{~m}$, the aspect ratio is $W / h=6.4$ and the median size of bed materials is $D_{50}=7.7 \mathrm{~mm}$. They have carried out experimental studies for more than a decade based on different bedforms geometry in laboratory scale, and compared their results to those of other researchers. They encountered a problem, namely, when the aspect ratio exceeds 10 in gravel-bed rivers, their laboratory results with small aspect ratio cannot be extended to field results. Does the change of aspect ratio affect the velocity profiles and Reynolds stress patterns? If yes, it will greatly change the estimation of roughness coefficient and other river processes including sediment transport. Up to date, some researchers have done interesting works based on field measurements in rivers for different objectives. MacVicar and Roy (2007) conducted field observations over pools and riffles with small lee side angle (downstream side of bedform) in some rivers in Province Quebec/Canada. They pointed out that it is necessary to better understand the interaction between bedforms, flow velocity and turbulence. Based on field data collected in some local rivers, Formann et al. (2007) tried to develop the relation between hydraulic and morphologic parameters using 2D and 3D models. Under the condition of uniform and steady flow, van der Mark et al. (2008) carried out experiments to study bedforms. Van der Mark et al. (2008) found that if the aspect ratio is less than 10, changes in bedform geometry decreases. They also claimed that the slope of lee side of bedform in flumes are considerable steeper than those in natural rivers.

Various factors in natural rivers have made the interaction of bedform and turbulence very complex. Despite the bedformsflow is very complicated, research work regarding the interaction of bedform and turbulence described by hydraulic and geometric parameters makes progress. Many researchers have studied river morphology with respect to fish habitat, sediment transport and channel evolution. However, only a few of them have investigated the relation between bedform dimensions and friction factor with aspect ratio.

Up to date, a number of methods have been presented to relate bedform dimensions to flow characteristics (e.g., Dey, 2014; Garcia, 2008; Julien, 2010; van Rijn, 1984; Yalin, 1992). Dimensional analysis shows that the main controlling parameters used to predict the bedform dimensions are dimensionless particle size $\left(D_{*}\right)$, relative roughness $\left(D_{50} / h\right)$ and dimensionless shear stress $\left(\tau_{*}\right)$ which will be described in the following section. For instance, to predict the bedform dimensions over dunes, van Rijn (1984) applied these parameters with particle diameters ranging from $0.19 \mathrm{~mm}$ to $0.23 \mathrm{~mm}$ for laboratory data and from $0.49 \mathrm{~mm}$ to $3.6 \mathrm{~mm}$ for natural rivers with an aspect ratio of larger than 3 and the flow depth more than $0.1 \mathrm{~m}$.

As pointed out by Julien and Klaassen (1995), to predict bedform dimensions, van Rijn's results showed a large variability for natural rivers under different conditions. Also, van Rijn's results under-estimated dimensions of bedforms under different morphodynamics conditions (Julien, 1992; Raslan, 
1991; Terms, 1986). The reasons may be caused that most studies were conducted in flumes under controlled conditions, and then to extend the results from model to prototype with unjustifiable assumptions. For example, in coarse-bed rivers, a wide range of bed materials is prevalent, therefore, the assumption of a uniform bed materials and uniform flow is not reasonable. Since the morphological condition in natural rivers is very complex, it is impossible to find well-recognized bedforms with a certain number of consecutive bed-surface fluctuations having both identical length and amplitude. Therefore, no classic term (e.g., dune, pool or riffle) can be assigned to the selected bedforms in this study.

River engineers know that the van Rijn's method was developed for dune-type bedform. Therefore, it may not be applied to the rivers with coarse bedforms. However, it should be mentioned that although van Rijn is known as pioneer who used some important parameters (e.g., $T$ and $D_{*}$ ) to predict the dune-bedform dimensions, it is necessary to extend the application of these important parameters to other bedforms in coarse-bed rivers.

To achieve this goal, several questions must be answered in unspecific bedforms of a coarse-bed river:

(i) What flow velocity and shear velocity should be used to calculate friction factor? Some researchers applied DoubleAveraging Method (DAM) over sharp-crest gravel dunes and pools (Fazlollahi et al., 2015a and b; Motamedi et al., 2014; Nasiri et al., 2010). Can this method be used to get required information over unspecific bedforms in a gravel-bed river in order to determine shear velocity and total friction factor?

(ii) Can one apply the important parameters for predicting dune characteristics to unspecific bedforms of a gravel-bed river using the double-averaging method? (iii) What role does play aspect ratio in the estimation of friction factor in unspecific bedforms?

\section{FIELD MEASUREMENTS}

\section{The study site}

Data for this study were collected in the Babolroud River in Mazandaran Province in northern Iran. This river originates from Alborz Mountains in Savadkooh and flows through two important cities, Babol and Babolsar, toward the Caspian Sea, showing the flow direction from south to north. The length of this river is about 78 kilometers. Some hydraulic structures such as bridges and dams are built along this river. To identify the dominant bedform of the river, the authors walked more than $60 \mathrm{~km}$ along this river. However, based on the criteria presented in reference books (Dey, 2014; Garcia, 2008; Julien, 2010; van Rijn, 1993), no classic bedform has been observed. For example, dunes have an approximately asymmetric triangular shape with a steep lee-side and gentle stoss-side. Therefore, four straight river reaches, namely, Anarestan reach; Daroonkola $1^{\text {st }}$ reach; Daroonkola $2^{\text {nd }}$ reach; and Klarikola reach, were selected with the average length of 89 meters and width of 22.7 meters. Sixteen cross sections in these reaches were selected for collecting more accurate information of bedform characteristics and hydraulic parameters such as discharge, water surface slope and velocity. Figure 1 illustrates geographic position of the selected river reaches and their distance from each other. Table 1 gives the features of the selected reaches including length and average width, number of cross sections in each reach and average of flow discharge in March and April. As shown in Table 1 , the flow in all 4 reaches is subcritical flow.

Table 1. Description of selected reaches.

\begin{tabular}{|c|c|c|c|c|c|c|c|}
\hline $\begin{array}{l}\text { Reach } \\
\text { number }\end{array}$ & Reach name & $\begin{array}{l}\text { Length } \\
\text { (m) }\end{array}$ & Width (m) & $\begin{array}{c}\text { No. of } \\
\text { sections }\end{array}$ & $\begin{array}{c}\text { Discharge } \\
\left(\mathrm{m}^{3} / \mathrm{s}\right)\end{array}$ & $F r$ & $\begin{array}{c}D_{50} \\
(\mathrm{~mm})\end{array}$ \\
\hline 1 & Anarestan & 90 & 19.5 & 5 & 5.4 & $0.2-0.69$ & $18.77-29.8$ \\
\hline 2 & Daroonkola $1^{\text {st }}$ & 67 & 24.4 & 3 & 4.3 & $0.31-0.54$ & $24-34.1$ \\
\hline 3 & Daroonkola $2^{\text {nd }}$ & 92 & 22.1 & 4 & 6.7 & $0.26-0.57$ & $26.55-39$ \\
\hline 4 & Klarikola & 107 & 24.7 & 4 & 5.6 & $0.24-0.86$ & $21.14-31.8$ \\
\hline
\end{tabular}

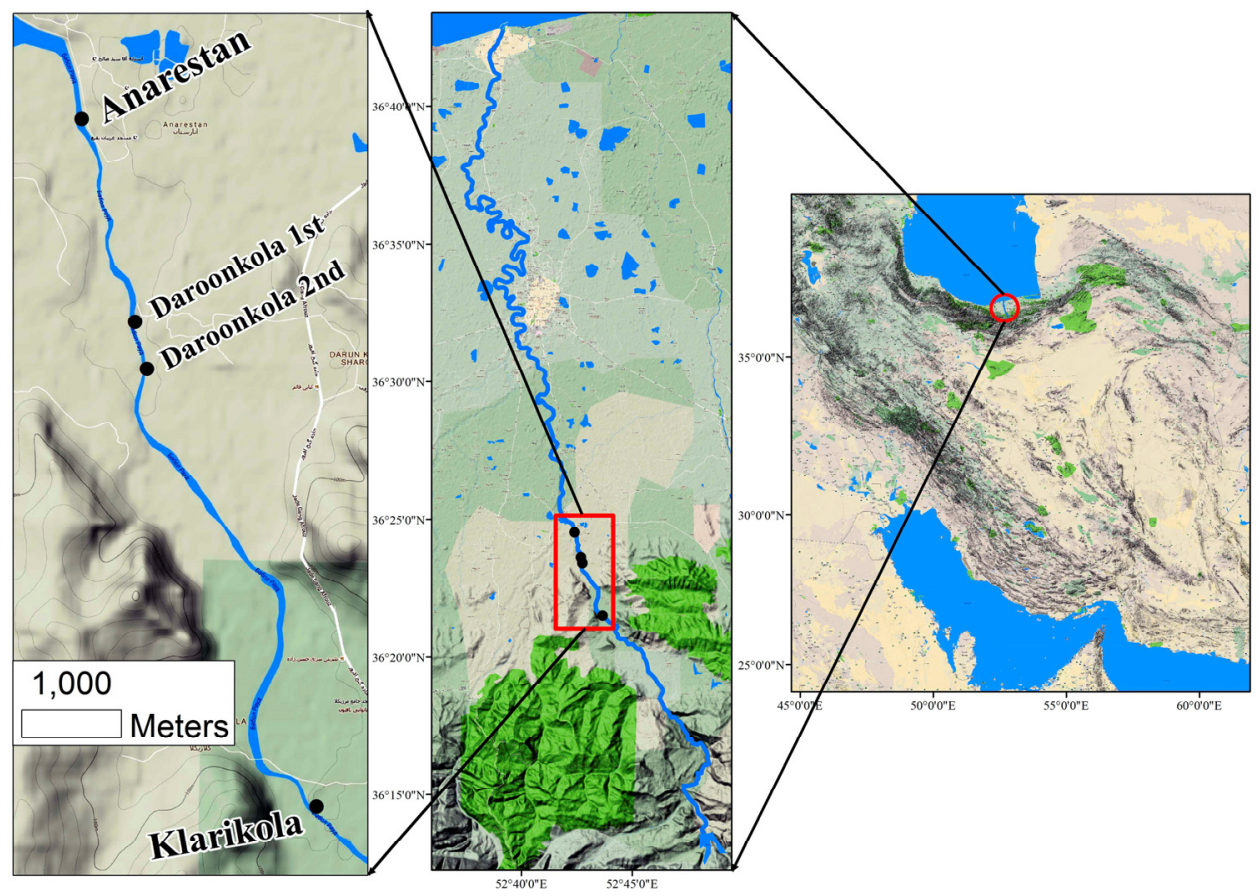

Fig. 1. Geographic map of the river and selected reaches. 


\section{Approaches for measurements}

After selecting the river reaches and appropriate cross sections (straight path along the river, without obvious obstacles such as boulders in river, vegetation along the banks and nonuniform flow), following variables along each cross section were measured: flow velocity, flow depth, water surface slope, particle size and riverbed bathymetry. Data collections have been conducted during two periods: the first period was in March and April during the high flow season in the Babolroud River. The second survey period was in June during relative low flow period, nearly 2 months after the first measurement period to ensure that the riverbed is stable.

\section{Anarestan}

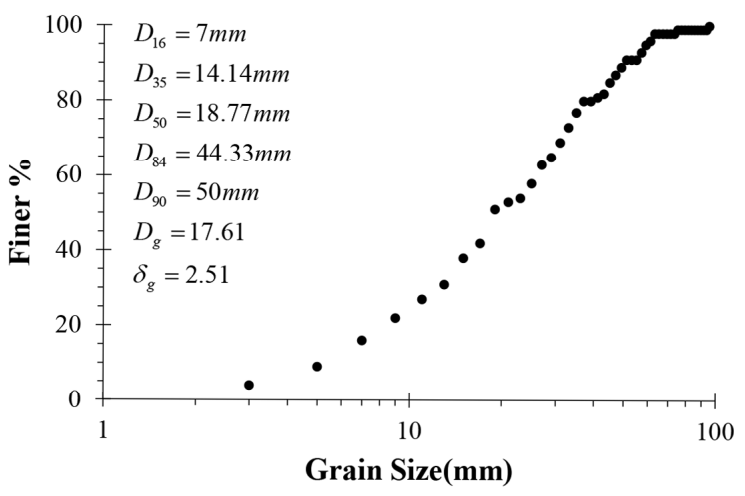

Daroonkola 2nd

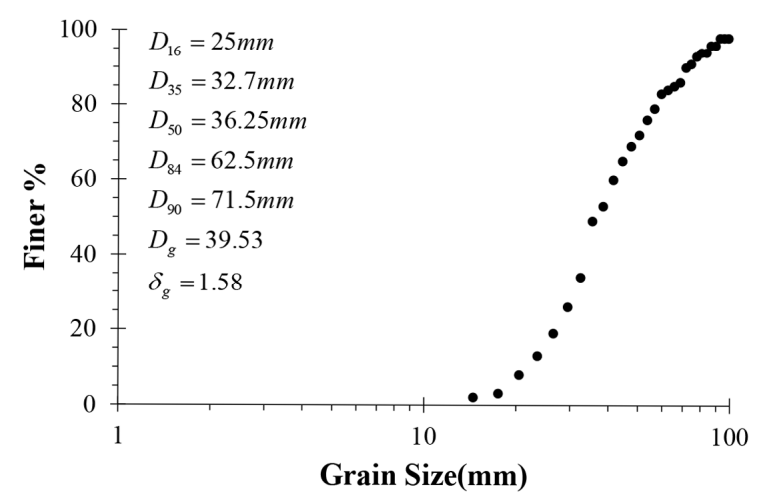

Fig. 2. Grain size distribution of bed materials.

\section{Daroonkola 1st}

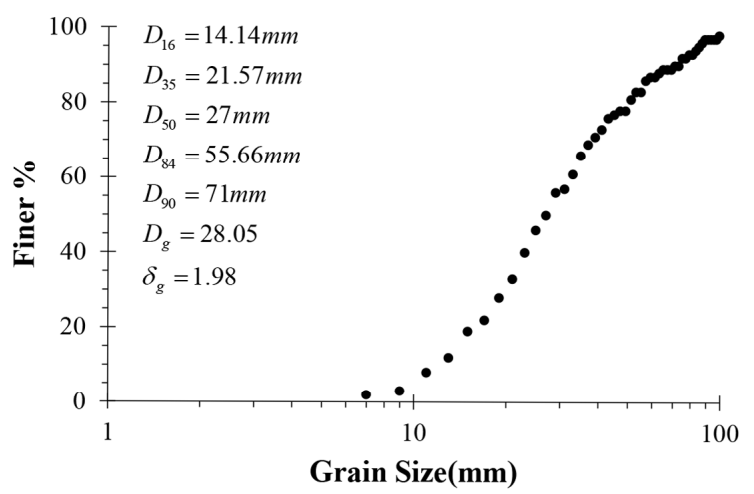

Klarikola

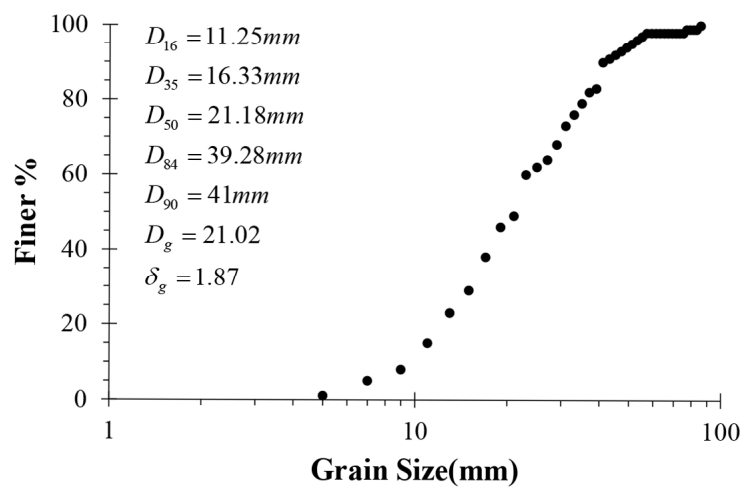

Anarestan

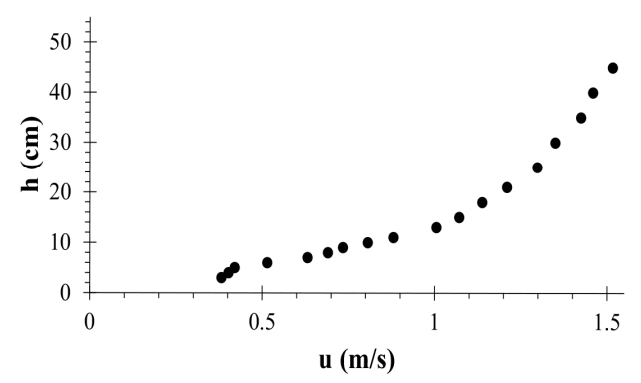

Daroonkola 2nd
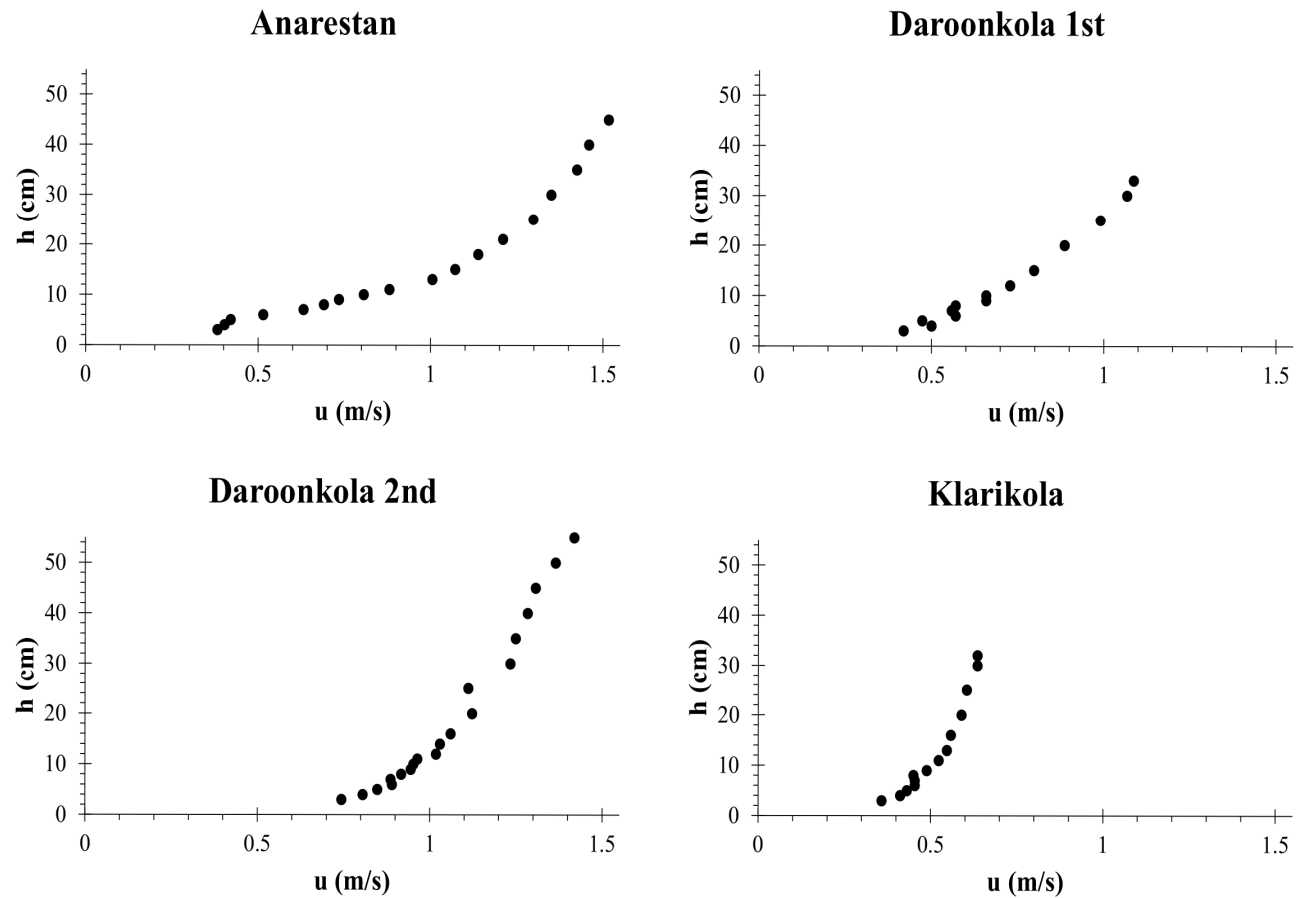

Klarikola

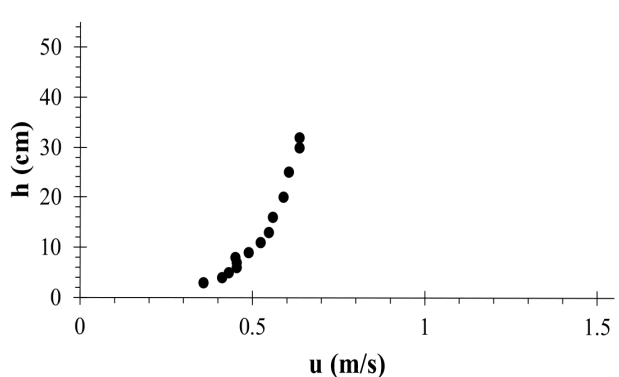

Fig. 3. Measured velocity profiles. 


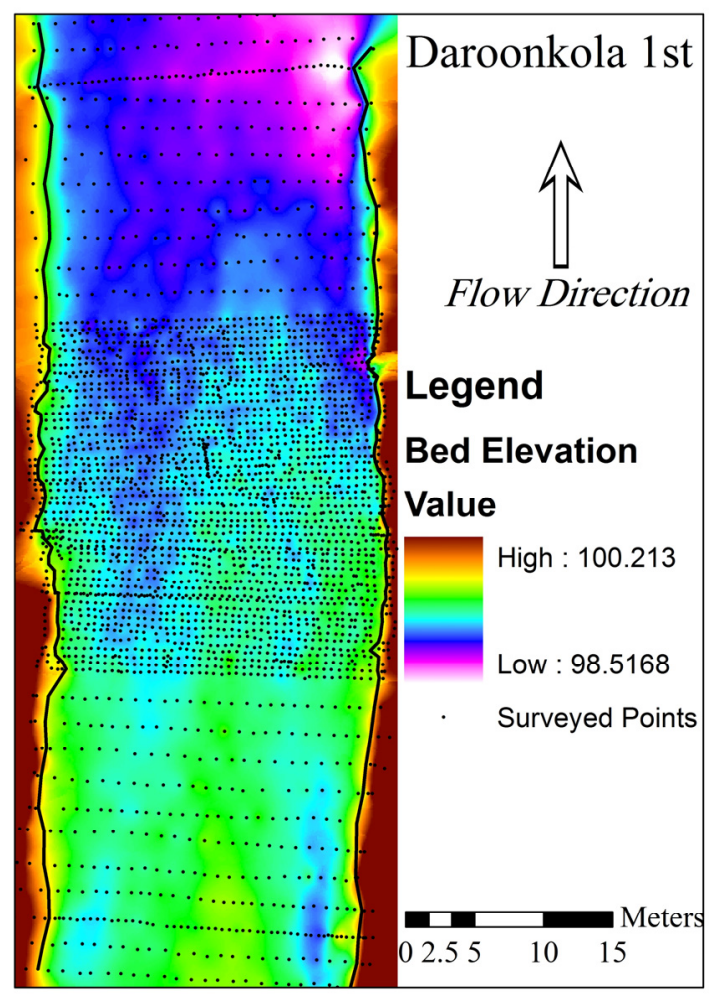

Fig. 4. The surveyed points and TIN map of a reach.

Grain size was obtained by following the Wolman (1954) pebble counts. In each cross section, 3 patches for measurement were chosen, left bank, right bank and center of the channel.

Along the axis of each river reach, in every $10 \mathrm{~m}$ or $5 \mathrm{~m}$, a patch was selected to measure particle size and its distribution. Figure 2 shows grain size distribution for four measurements in which the geometric standard deviation and mean grain size were defined as $\delta_{g}=\left(D_{84} / D_{16}\right)^{0.5}$ and $D_{g}=\left(D_{84} \cdot D_{16}\right)^{0.5}$, respectively.

A current-meter made by Vale Port Company in England was used to measure point velocity at different flow depths. In each section, 3 to 6 velocity profiles with 7 to 19 point velocities were measured. Also, at a distance of every $5 \mathrm{~m}$ or $10 \mathrm{~m}$ along the central axis of each river reach, one velocity profile with 7 to 18 point velocities was measured. In addition, mean point velocities at each cross section were determined at a relative flow depth of 0.2 and 0.8 for each $1 \mathrm{~m}$ in width across the river to better estimate the flow discharge of the river. The collection period of each point velocity measurement in a profile was 50 seconds with at least 3 repetitions to avoid the effect of time variation on the results. Figure 3 illustrates flow velocity profiles. All measurements were conducted in dominant discharge. For Anarestan, the profile was taken from the third cross section (see Figure 7) along the central axis of this river reach which has a flow discharge of $6.9 \mathrm{~m}^{3} / \mathrm{s}$. For Daroonkola reach, the profiles were taken at the points in the second and third cross sections. These points were located $15 \mathrm{~m}$ from the left bank and the central axis. The flow discharge was 5.12 $\mathrm{m}^{3} / \mathrm{s}$. For Klarikola reach, the velocity profile was taken from the point in the third cross section which was 5 meters from the right bank. The flow discharge for this river reach was $7.3 \mathrm{~m}^{3} / \mathrm{s}$.

To survey the topography of river reaches, the bed slope and the water surface slope, a Leica total station camera (TC 1700) with the accuracy of 1.7 seconds was used. In order to reduce errors caused by equipment, the distance between the camera and the upstream cross section of the river reach was nearly equals to that of to the downstream cross section. Two points were selected to check whether the camera was set up correctly or not: one point was located at the starting point of the river reach and another at the end of river reach. Before starting any survey, the coordinates of these 2 points were surveyed. If the difference was only 1 millimeter or less, the surveying operations started. Ropes were used over water surface to construct an almost regular network grid on riverbed. The intervals of the network grids have following dimension (length $\times$ width): $0.5 \mathrm{~m} \times 0.5 \mathrm{~m}, 1 \mathrm{~m} \times 1 \mathrm{~m}$ and $2 \mathrm{~m} \times 1 \mathrm{~m}$, where the first number is the grid length along the flow direction, and another one is the grid width cross the river (perpendicular to flow direction). By using these networks, the average point density (for measurements) was about 1.85 points per square meters. Figure 4 shows density of surveyed points plus Triangular Irregular Network (TIN) map of bed elevation for one of the study river reaches. Riverbed elevation and surveyed points can be observed in the legend of this figure. Table 2 shows the point density of each river reach and the area that water flows. After

Table 2. Characteristics of studied river reaches.

\begin{tabular}{lccc}
\hline Reach name & $\begin{array}{c}\text { Area } \\
\left(\mathrm{m}^{2}\right)\end{array}$ & $\begin{array}{c}\text { Number of } \\
\text { surveyed points }\end{array}$ & $\begin{array}{c}\text { Point density } \\
\left(\text { points } / \mathrm{m}^{2}\right)\end{array}$ \\
\hline Anarestan & 1761 & 4894 & 2.78 \\
Daroonkola 1 $^{\text {st }}$ & 1636 & 3292 & 2.01 \\
Daroonkola 2 $^{\text {nd }}$ & 2034 & 2597 & 1.27 \\
Klarikola & 2649 & 3574 & 1.35 \\
\hline
\end{tabular}
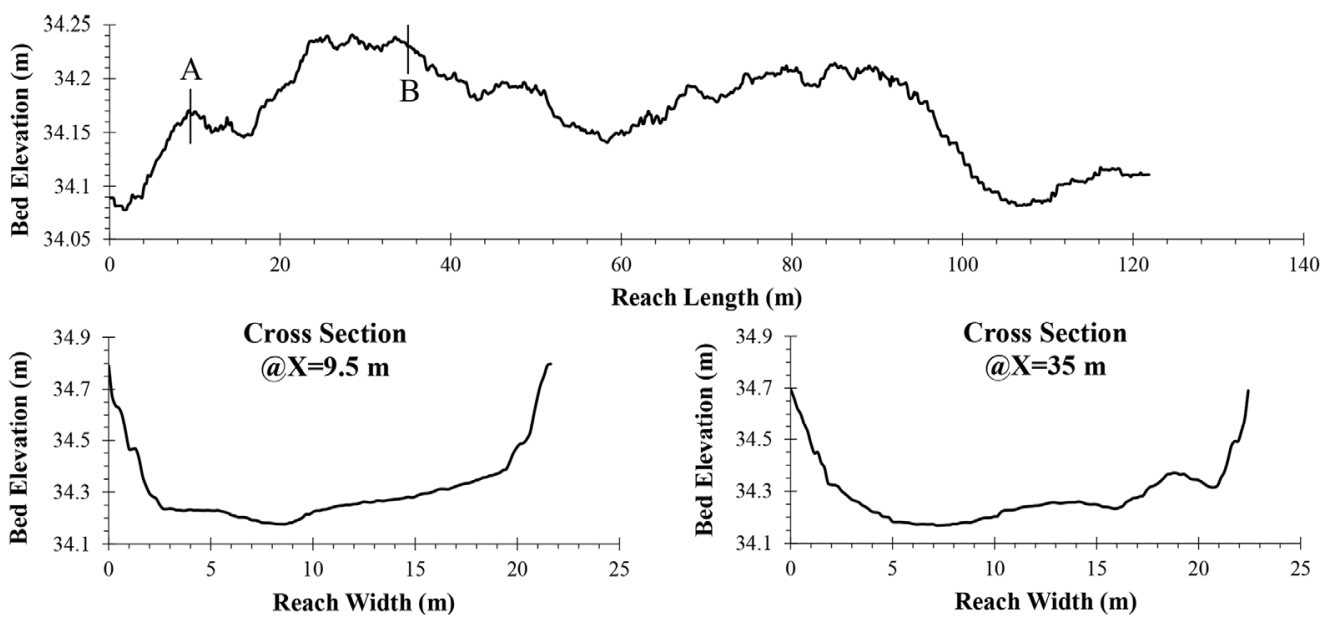

Fig. 5. Longitudinal profile of Daroonkola 2nd and the shape of cross sections (9.5 $\mathrm{m}$ and $35 \mathrm{~m}$ from upstream of the longitudinal profile). 


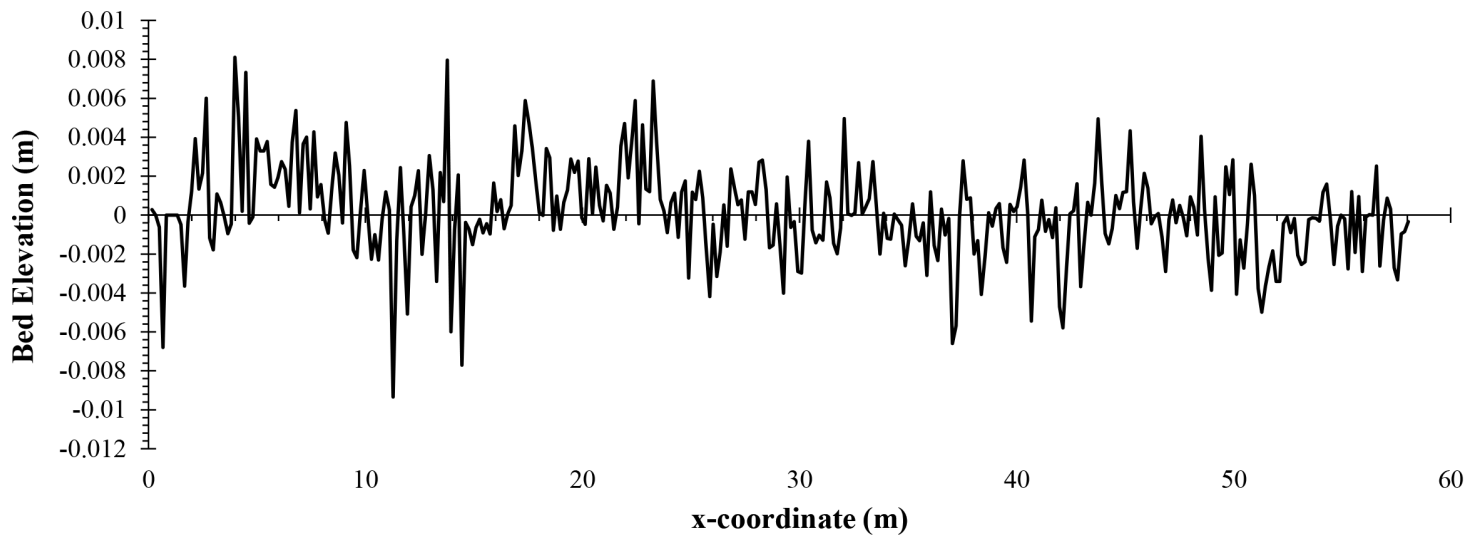

Fig. 6. The detrended river bed using bedform tracking tool.
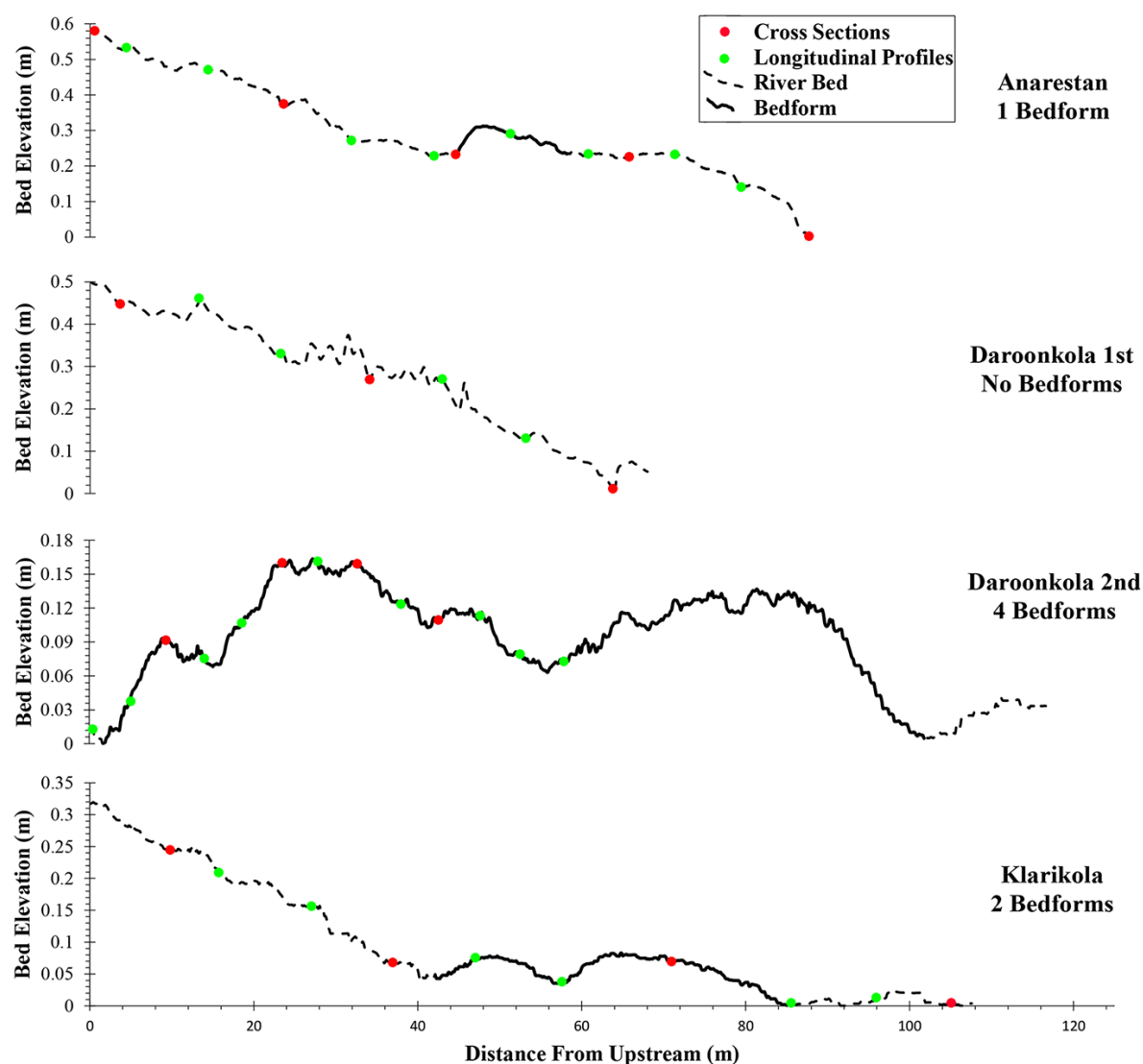

Fig. 7. The seven unspecific bedforms selected in the reaches.

collecting data, the bathymetry was obtained from a pointbased TIN. By inputting data into the surveying software, it was observed that the network of $1 \mathrm{~m} \times 1 \mathrm{~m}$ grid was easier than the first grid $(0.5 \mathrm{~m} \times 0.5 \mathrm{~m})$ for surveying, but showing the same survey accuracy for gravel-bed rivers. Also, the third survey grid $(2 \mathrm{~m} \times 1 \mathrm{~m})$ gives the reasonable information about unspecific bedforms and topographic changes of riverbed. Using the selected grids, Figure 5 illustrates two cross sections and the longitudinal bed profile of a selected river reach along the central axis. All surveying operations were conducted in March and April.

\section{CALCULATIONS \\ Friction factor with bedforms}

Based on data collected for riverbed, the topographic maps of each reach were plotted; the longitudinal profiles of river bed for the central axis of each reach were also presented. In this way, the bedforms are detectable and their dimensions can be measured by means of detail surveying. There are several methods to find the crest location and trough location, and then to determine the geometric characteristics of individual bedforms (van der Mark et al., 2008). A bedform-tracking tool was 
developed by van der Mark and Blom (2007). By using this bedform-tracking tool, several bedforms with very small length and height could be identified. It is impossible to measure flow characteristics over all the identified bedforms in study river reaches. Therefore, using smooth filter method by considering the places where flow measurements were conducted, seven bedforms were selected in study river reaches. Figure 6 illustrates the detrended riverbed for locating bedforms. Figure 7 shows seven selected bedforms in four study river reaches. The steepness and the ratio of bedform height to bedform length were used in van Rijn method.

Van Rijn (1984) developed the following equations:

$$
\begin{aligned}
& \frac{\Delta}{h}=0.11\left(\frac{D_{50}}{h}\right)^{0.3}\left(1-e^{-0.5 T}\right)(25-T) \\
& \frac{\Delta}{\Lambda}=0.015\left(\frac{D_{50}}{h}\right)^{0.3}\left(1-e^{-0.5 T}\right)(25-T)
\end{aligned}
$$

where, $\Delta$ and $\Lambda$ are the bedform height and bedform length, respectively; $D_{50}$ is median bed particle diameter in which 50 percent of particles are smaller than it; $h$ is flow depth and $T$ is transport-stage parameter which shows the effect of dimensionless shear stress and is defined by van Rijn as:

$$
T=\frac{\left(u_{*}^{\prime}\right)^{2}-\left(u_{*_{c}}\right)^{2}}{\left(u_{*_{c}}\right)^{2}}
$$

where $u_{*}^{\prime}$ is grain shear velocity which is a measure of velocity gradient due to the bed grains and $u_{*_{c}}$ is critical grain shear velocity due to threshold of motion of grains.

Equations 1 to 3 are developed by van Rijn for sand-bed streams. These equations and parameters in the equations were obtained by regressional and dimensional analysis. They may be used beyond of their application ranges. Accordingly, the flow depth $h$ and the transport-stage parameter $T$ can be determined using Equations 1 and 3, respectively. In fact, once $T$ is determined from equation 3 , the only unknown parameter in equation 1 is $h$. In this study, the value of critical shear stress, $u_{*_{c}}$, was calculated from the Shield's diagram (Dey, 2014). Since the median grain size of particles investigated herein is larger than $6 \mathrm{~mm}$, from the Shield's diagram, the $\tau_{*}$ has a constant value of 0.06 in the fully rough turbulent flow region. Therefore, $u_{*_{c}}$ can be calculated as follows:

$u_{*_{c}}=\sqrt{0.06 g(S G-1) D_{50}}$

where, $g$ is gravitational acceleration and $S G=\rho_{s} / \rho$. Also, the dimensionless grain diameter can be determined as:

$D_{*}=\left[\frac{g(S G-1)}{v^{2}}\right]^{1 / 3} D_{50}$

where, $v$ is kinematic viscosity.

The grain shear velocity, $u_{*}^{\prime}$, can be calculated by using empirical methods. Herein, three methods were considered: the first one was suggested by van Rijn by using roughness due to grain size, $C$ '; the second one is by using the boundary-layer characteristics method (BLCM) (Afzalimehr and Rennie, 2009) and the third one is by replacing $c$ (Chezy coefficient) instead of $C^{\prime}$ which is defined by Equation 7. In the first method proposed by van Rijn, grain shear velocity can be written as:

$u_{*}^{\prime}=u \frac{\sqrt{g}}{C^{\prime}}$

in which

$$
C^{\prime}=18 \log \left(\frac{12 R_{b}}{3 D_{90}}\right)=7.82 \ln \left(\frac{12 R_{b}}{3 D_{90}}\right)=\frac{\sqrt{g}}{0.4} \ln \left(\frac{12 R_{b}}{3 D_{90}}\right)
$$

where $u$ is the depth-averaged flow velocity; $R_{b}$ is the hydraulic radius related to channel bed and calculated from method proposed by Vanoni and Brooks (1957) that for wide channels, $R_{b}$ $=h$; and $D_{90}$ is the grain size in which 90 percent of the particles are finer than it. Combining Equations 6 and 7, following equation is yielded:

$$
\frac{u}{u_{*}^{\prime}}=\frac{1}{0.4} \ln \left(\frac{12 h}{3 D_{90}}\right)
$$

On the other hand, the logarithmic distribution of velocity profile is presented as:

$$
\frac{u}{u_{*}^{\prime}}=\frac{1}{k} \ln \left(\frac{h}{K_{s}^{p}}\right)
$$

where $k$ is von Karman coefficient and has the average value of 0.4 . This value of $k$ has been reported by different researchers (e.g., Afzalimehr, 2010; Kironoto and Graf, 1994). These researchers pointed out that this value of $k=0.4$ is reasonable for gravel and cobble bed streams when there is no vegetation in riverbanks and riverbed, no significant obstacle (boulder) and suspended sediment particles in flow. By comparing equation 8 to equation 9 , it is found that $K_{s}^{p}=0.25 D_{90}$. For the case of flow over bedforms, total grain roughness is the combination of roughness caused by grains and bedforms showing as $K_{s}=K_{s}^{p}+K_{s}^{b}$. Scientists have presented different values for $K_{s}^{p}$ in the form of $\alpha D_{\beta}$ in which $\alpha$ and $\beta$ take different values (e.g., $\alpha=3$ and $\beta=90$ presented by van Rijn (1984)). For roughness caused by bedforms, van Rijn presented the following equation:

$$
K_{s}^{b}=1.1 \Delta\left(1-e^{-25 \Delta / \Lambda}\right)
$$

Therefore, the total friction factor can be calculated as:

$$
f=f^{\prime}+f^{\prime \prime}
$$

where $f^{\prime}$ and $f^{\prime \prime}$ are friction due to grains and bedforms, respectively. The friction factor due to particles can be estimated as:

$$
\frac{1}{f^{0.5}}=2.03 \log \left(\frac{12.2 h}{k_{s}}\right)
$$

or

$f^{\prime}=\left[2.03 \log \left(\frac{12.2 h}{k_{s}}\right)\right]^{-2}$ 
The total $f$ may be determined as:

$f=8\left(u_{*} / u\right)^{2}$

where the total shear velocity $(u *)$ is calculated by using the BLCM method (Afzalimehr and Anctil, 2000) as follow:

$u_{*}=\frac{\left(\delta_{*}-\theta\right) u_{\max }}{C \delta_{*}}$

where, $C$ is a constant depending on flow condition and has to be evaluated. Afzalimehr and Anctil (2000) and Afzalimehr and Rennie (2009) claimed $C=4.4$ using based on laboratory experiments and field studies, respectively; $u_{\max }$ is the maximum flow velocity in a velocity profile; $\delta_{*}$ is the displacement thickness; and $\theta$ is the momentum thickness. According to Schlichting and Geresten (2000), these thicknesses are defined as:

$$
\begin{aligned}
& \delta_{*}=\int_{0}^{h}\left(1-\frac{u}{u_{\max }}\right) d y \\
& \theta=\int_{0}^{h} \frac{u}{u_{\max }}\left(1-\frac{u}{u_{\max }}\right) d y
\end{aligned}
$$

The importance of using the BLCM method is that Equation 15 not only uses the boundary-layer characteristics, but also it contains the effect of non-uniformity of bed via a velocity profile. This non-uniformity is due to flow variation over bedform. Therefore, BLCM takes into account both grain friction and form friction, using the shape of velocity profile.

The third method is the modified van Rijn's method using Chezy coefficient as follow:

$u_{*}^{\prime}=u \frac{\sqrt{g}}{c^{\prime}}$

$c^{\prime}=\frac{u}{\sqrt{h^{\prime} s}}$

where, $c^{\prime}$ is the grain Chezy coefficient, $h^{\prime}$ is bed flow depth and $s$ is the averaged bed slope of a reach. In this study, considerable points in 4 river reaches were measured along the riverbed in order to calculate the bed slope accurately instead of determining it only using the first point and the end point of the river reach. Figure 8 illustrates calculated slope for each bedform. The bold line considers the variations of riverbed on slope, showing the accurate slope determined by this method.

To determine friction factor $(f)$ or total Chezy coefficient (c), following relations was applied (Julien, 2010):

$$
c \sqrt{\frac{8 g}{f}}=5.75 \sqrt{g} \log \left(12 \frac{R_{b}}{K_{s}}\right)
$$

where $K_{s}$ is the total grain roughness parameter suggested by van Rijn which depends not only on the grain roughness size $\left(K_{s}^{\prime}\right)$, but also on the bedform length $(\Lambda)$ and the bedform height $(\Delta)$.

$K_{s}=3 d_{50}+1.1 \Delta\left(1-e^{-25 \Delta / \Lambda}\right)$

Also, Yalin's method to calculate the Chezy coefficient was considered as follow:

$$
c=\frac{u}{u_{*}}=\frac{1}{\sqrt{\frac{1}{\left[(1 / k) \ln \left(11 h / K_{s}^{\prime}\right)\right]^{2}}+\frac{1}{2}\left(\frac{\Delta}{\lambda}\right)^{2} \frac{\Delta}{h}}}
$$

in which

$$
K^{\prime}{ }_{s}=2 d_{50}
$$

\section{Method of double-averaged velocity}

To resolve the spatial heterogeneity in streams with bedform, the time-averaging method is conceptually supplemented by the area-averaging method in the layer parallel to the mean bed surface called the double-averaging methodology (Dey, 2014). Nikora et al. (2001) defined the double-averaged velocity over a specific horizontal plane at level $z$, as below:

$$
\langle\bar{u}\rangle=\frac{1}{A_{f}(z)} \int_{\Omega} \bar{u}(\alpha, \beta, z) d s
$$

where $\Omega$ is horizontal domain parallel to the river bed with the area of $L_{x} \times L_{y}$ located at level $z$; function $A_{f}(z)$ is void distribution corresponding to the fraction of the area occupied by the fluid at a given elevation of $z$; and dummy variables $\alpha$ and $\beta$ are such that $0<\alpha<L_{x}$ and $0<\beta<L_{y}$.

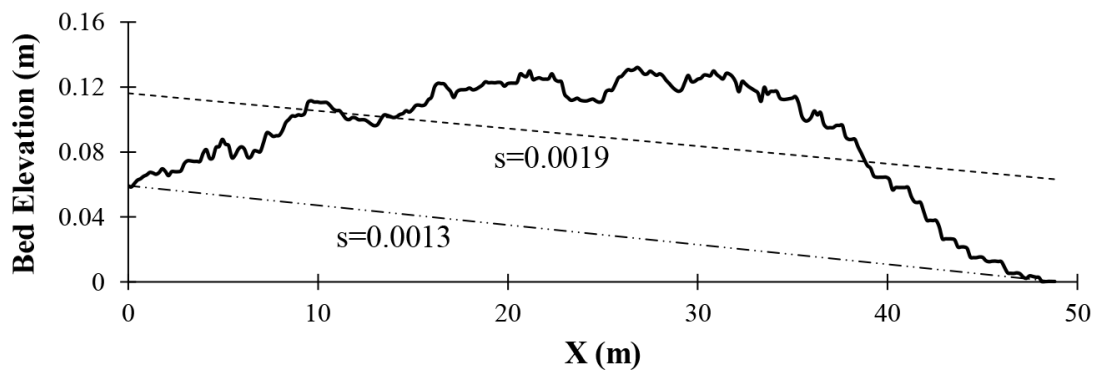

Fig. 8. Calculation of the slope of river bed. 
Table 3. Bedform dimensions and calculated parameters.

\begin{tabular}{|c|c|c|c|c|c|c|c|c|c|c|}
\hline Bedforms & $\begin{array}{c}\Delta \\
(\mathrm{m})\end{array}$ & $\begin{array}{c}\Lambda \\
(\mathrm{m})\end{array}$ & $\begin{array}{c}h \\
(\mathrm{~m})\end{array}$ & $\begin{array}{c}u *_{c r} \\
(\mathrm{~m} / \mathrm{s})\end{array}$ & $\begin{array}{c}u_{*}^{\prime}(1) \\
(\mathrm{m} / \mathrm{s})\end{array}$ & $T$ & $\begin{array}{c}u_{*} \\
(\mathrm{~m} / \mathrm{s})\end{array}$ & $T$ & $\begin{array}{c}u_{*}^{\prime}(3) \\
(\mathrm{m} / \mathrm{s})\end{array}$ & $T$ \\
\hline 1 & 0.083 & 14.17 & 0.46 & 0.16 & 0.13 & 0.33 & 0.16 & 0.00 & 0.35 & 3.96 \\
\hline 2 & 0.042 & 15.00 & 0.42 & 0.15 & 0.09 & -0.52 & 0.11 & -0.46 & 0.25 & 2.24 \\
\hline 3 & 0.082 & 27.63 & 0.40 & 0.14 & 0.09 & -0.59 & 0.11 & -0.38 & 0.23 & 1.76 \\
\hline 4 & 0.060 & 13.91 & 0.55 & 0.18 & 0.10 & -0.67 & 0.11 & -0.62 & 0.26 & 1.17 \\
\hline 5 & 0.076 & 27.04 & 0.44 & 0.17 & 0.09 & -0.69 & 0.13 & -0.41 & 0.25 & 1.27 \\
\hline 7 & 0.102 & 48.80 & 0.45 & 0.18 & 0.12 & -0.52 & 0.08 & -0.80 & 0.31 & 2.14 \\
\hline
\end{tabular}

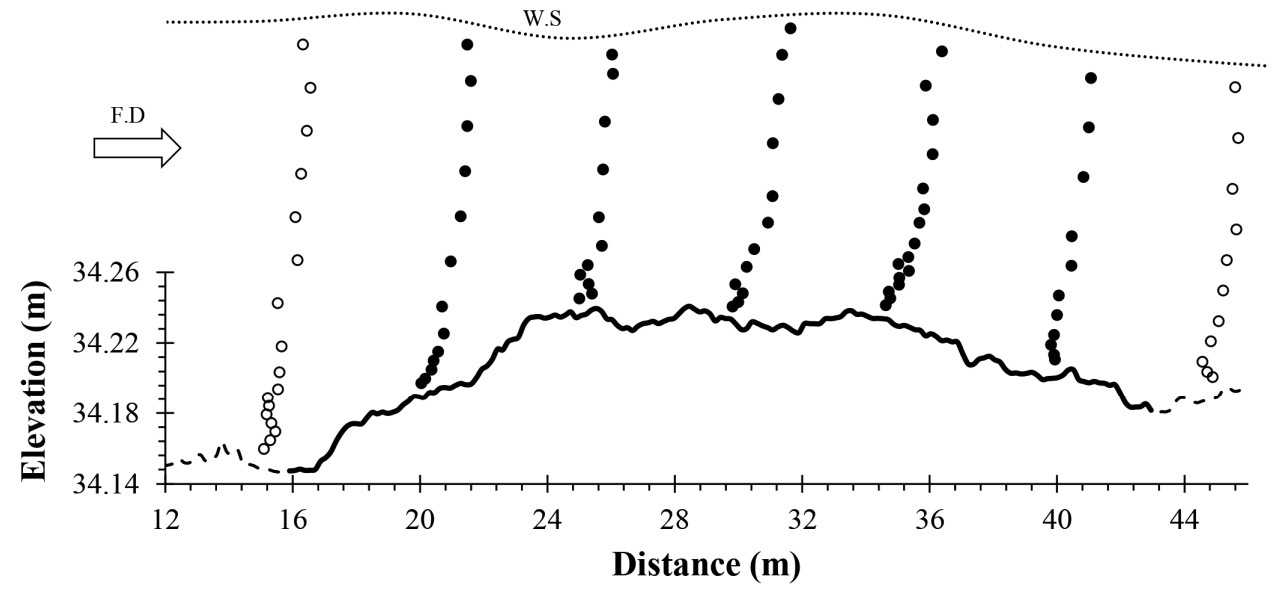

Fig. 9. The measured velocity profiles over an unspecific bedform.

Double-Averaged Velocity Profile

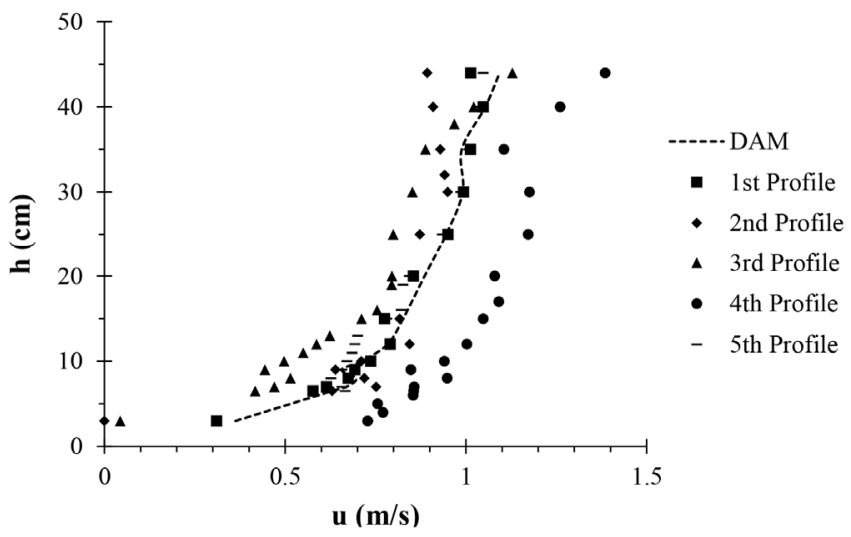

Fig. 10. Application of double-averaging method in the gravel bedforms (profiles were presented in the Figure 9 in Bold; the $1^{\text {st }}$ profile is located at $x=20 \mathrm{~m} \ldots .$. the $5^{\text {th }}$ one is located at $x=40 \mathrm{~m}$ ).

The flow depth and shear velocity for each bedform are also the average of different depths. The shear velocities are calculated by double-averaging method along of each bedform. Figure 9 shows the bedform of Daroonkola reach with measured velocity profiles and Figure 10 shows application of the double-averaging method for the bedform of this river reach. In Figure 9, the horizontal axis shows the distance from the upstream cross section of the second river reach in Daroonkola reach. All profiles were measured along the central longitudinal axis of river.

Table 3 presents the bedform dimensions including height $(\Delta)$ and length $(\Lambda)$; the measured flow depth; critical shear velocity; the grain shear velocity $u_{*}^{\prime}(1)$ calculated using Equation 6 and $u_{*}^{\prime}$ (3) calculated using Equation 18; $u_{*}$ determined using the BLC method (Equation 15) and also transport-stage parameter $(T)$ calculated by the mentioned methods.

\section{RESULTS AND DISCUSSION Results}

Considering the first objective of this research and observed from Figures. 3, 7 and 9, one can clearly say that application of a single profile at a specific location over a bedform cannot be representative, showing the necessity of using more robust techniques to estimate mean velocity and shear velocity in order to make a better prediction from the friction factor. Figure 10 shows that the double averaged method can be used reasonably to present a suitable mean velocity profile and then to determine shear velocity and friction factor over an unspecific bedform in a gravel-bed river.

The significant parameters were developed by van Rijn and Yalin for dunes in sand-bed rivers to predict the friction factor. Regarding the second objective, the significant parameters were applied to predict the friction factor over unspecific bedforms in different reaches of a gravel-bed river. Figure 11 shows the comparison of Chezy coefficient calculated using Equations 20 and 22. In gravel-bed streams with bedforms, application of Equation 20 to present the roughness effect is appropriate because it considers the dimensions of bedforms (Figure 11). Figure 11 shows the difference between two methods for calculating $K_{s}$ for gravel-bed rivers. As bedforms and grain size of riverbed play vital roles in calculation of $K_{s}$, higher values of $K_{s}$ calculated by van Rijn are more realistic; showing better performance of van Rijn's method than Yalin's method in this study, as shown in Figure 11. 
Friction factor over bedforms is different from that over the flat bed because bedforms cause flow separation and considerable kinetic energy dissipation. Therefore, it is required to apply total friction consists of particle friction and form friction instead of only particle friction. Using Equations 13 and 14, the value $f^{\prime \prime}$ can be calculated by Equation 11. Table 4 presents a summary of friction factor calculations. As shown in Table 4, the contribution of form friction in total friction is considerable. Thus, neglecting the form friction will significantly underestimate friction factor used in hydraulic models.

Figure 12 displays the bedform dimensions and variations in water surface elevation, velocity and shear velocity, Froude number and Reynolds number, grain size and sediment distribution along the bedform. Accordingly, for a river reach of $17 \mathrm{~m}$ long, it is noticed that there are considerable variations in riverbed elevation, shear velocity and grain size. One can see from Figure 12, from upstream to the crest of each bedform, the flow is decelerating, exactly opposite of dunes stoss (upstream side of bedform). Also, in this region, shear velocity increases, but not up to critical value to move coarse particles.

It should be mentioned that van der Mark and Blom (2007) proposed a bedform tracking tool which may be used to predict the geometric variables of an individual bedform from the original bed elevation profiles. The application of this bedform tracking tool was not useful for the present study river reaches due to the high value of $K_{s}$. To make this tool more applicable in coarse-bed rivers, more research is required.

Figure 13 displays variations in aspect ratio with friction factor, revealing a variable changes along the bedform. In downstream side (lee side) of each bedform, an increase in aspect ratio is observed. In general, it is difficult to draw a clear relationship between aspect ratio and friction factor over unspecific gravel-bedforms; this is confirmed by the presented results in Table 4 . Table 4 presents the results for the average aspect ratio and average friction factor.

\section{Discussion}

Figure 14 illustrates the effects of Froude number, bed slope, dimensionless grain size and the ratio of shear velocity to its critical value on bedform steepness. As shown in Figure 14, a decrease in Froude number leads to a decrease in the height of bedform and thus results in the formation of a flat bed. This finding confirms van Rijn's statement (Dey, 2014) where T>25 a flat-bed flow will be generated. Regarding the effect of dimensionless grain size on the steepness of bedform, a decrease in sediment sizes results in an increase in the steepness of bedform $(\Delta / \Lambda)$, because the flow can carry more finer sediment particles.

Comparison between grain shear velocity determined by van Rijn's method by using roughness and shear velocity determined by the boundary-layer method $\left(u_{* \text { bou }}\right)$ shows that both methods present approximately similar values for bedforms of 2 to 7. However, the grain shear velocity determined by using $c$ instead of $C^{\prime}$ shows a significant different from that by using the boundary-layer method $\left(u_{* b o u}\right)$.

Following two hypotheses may be used to explain the difference between calculated grain shear velocities (by means of different methods) and critical shear velocities:

1) The first hypothesis is that bedforms dimensions of the selected gravel-bed river were generated during a high flow with the average flow depth and shear velocity of much more than $0.44 \mathrm{~m}$ and $0.1 \mathrm{~m} / \mathrm{s}$, respectively. Therefore, van Rijn's method can be applied in gravel-bed rivers if such a high flow generates the bedforms, but this method is not applied under normal flow condition. 2) The second hypothesis is that van Rijn's method was calibrated with small particles size (sand-bed). Therefore, application van Rijn's method in gravel-bed rivers leads to underestimation of bedforms dimensions in gravel-bed rivers.

Table 4. Bedform characteristics, aspect ratio and friction factors.

\begin{tabular}{lccccccc}
\hline Bedforms & $\frac{\Delta}{\Lambda}$ & $K_{s}^{p}$ & $K_{s}^{b}$ & $W / h$ & $f^{\prime}$ & $f^{\prime \prime}$ & $f$ \\
\hline 1 & 0.006 & 0.156 & 0.012 & 42.47 & 0.058 & 0.121 & 0.179 \\
2 & 0.003 & 0.144 & 0.003 & 32.46 & 0.059 & 0.075 & 0.134 \\
3 & 0.003 & 0.1425 & 0.006 & 43.44 & 0.059 & 0.100 & 0.159 \\
4 & 0.004 & 0.2243 & 0.006 & 56.10 & 0.063 & 0.092 & 0.155 \\
5 & 0.003 & 0.1734 & 0.0057 & 56.77 & 0.062 & 0.086 & 0.148 \\
6 & 0.002 & 0.1955 & 0.0022 & 65.23 & 0.069 & 0.028 & 0.097 \\
7 & 0.002 & 0.228 & 0.0057 & 72.17 & 0.07 & 0.018 & 0.088 \\
\hline
\end{tabular}

Calculation Dimensionless Chezy Friction Factor

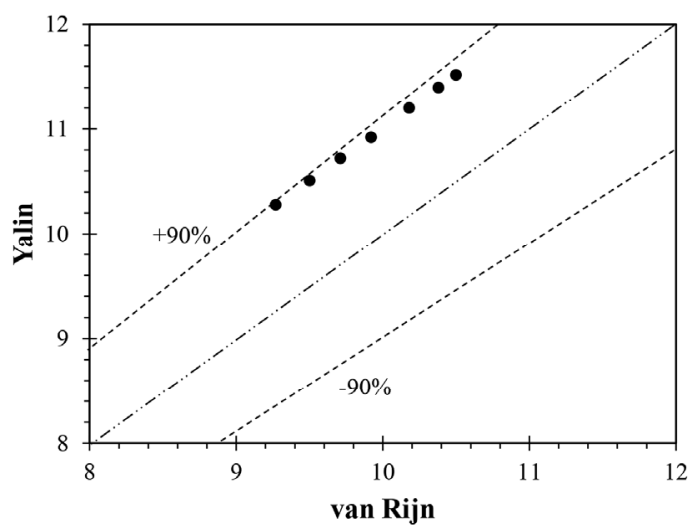

Calculation Ks

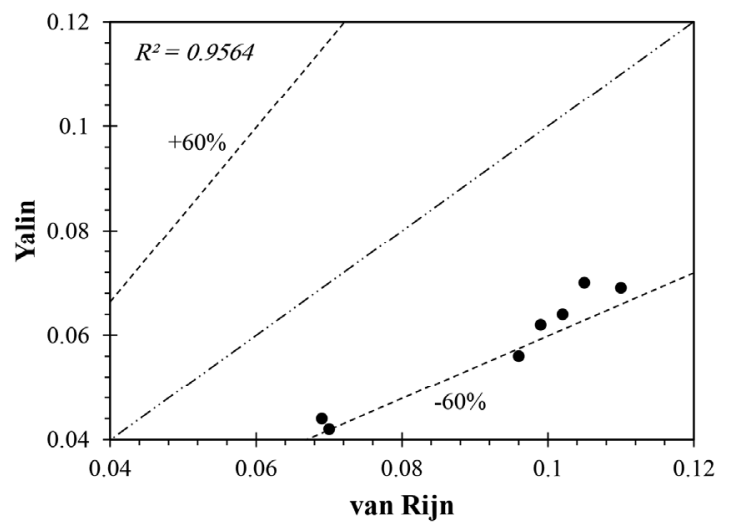

Fig. 11. Comparison of estimated Chezy Coefficient and $K_{s}$ using van Rijn and Yalin's methods. 


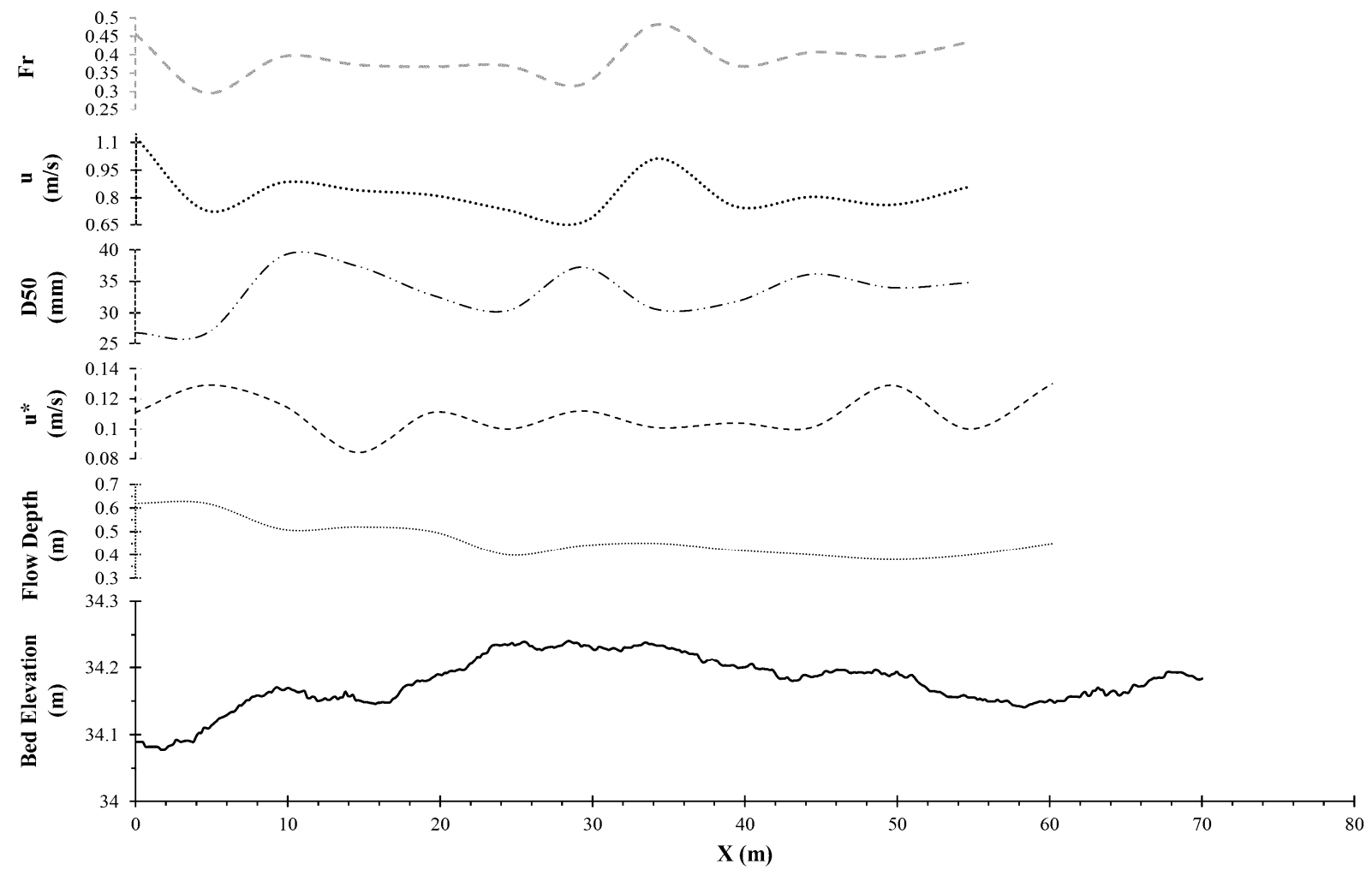

Fig. 12. Distribution of flow parameters along a river reach.

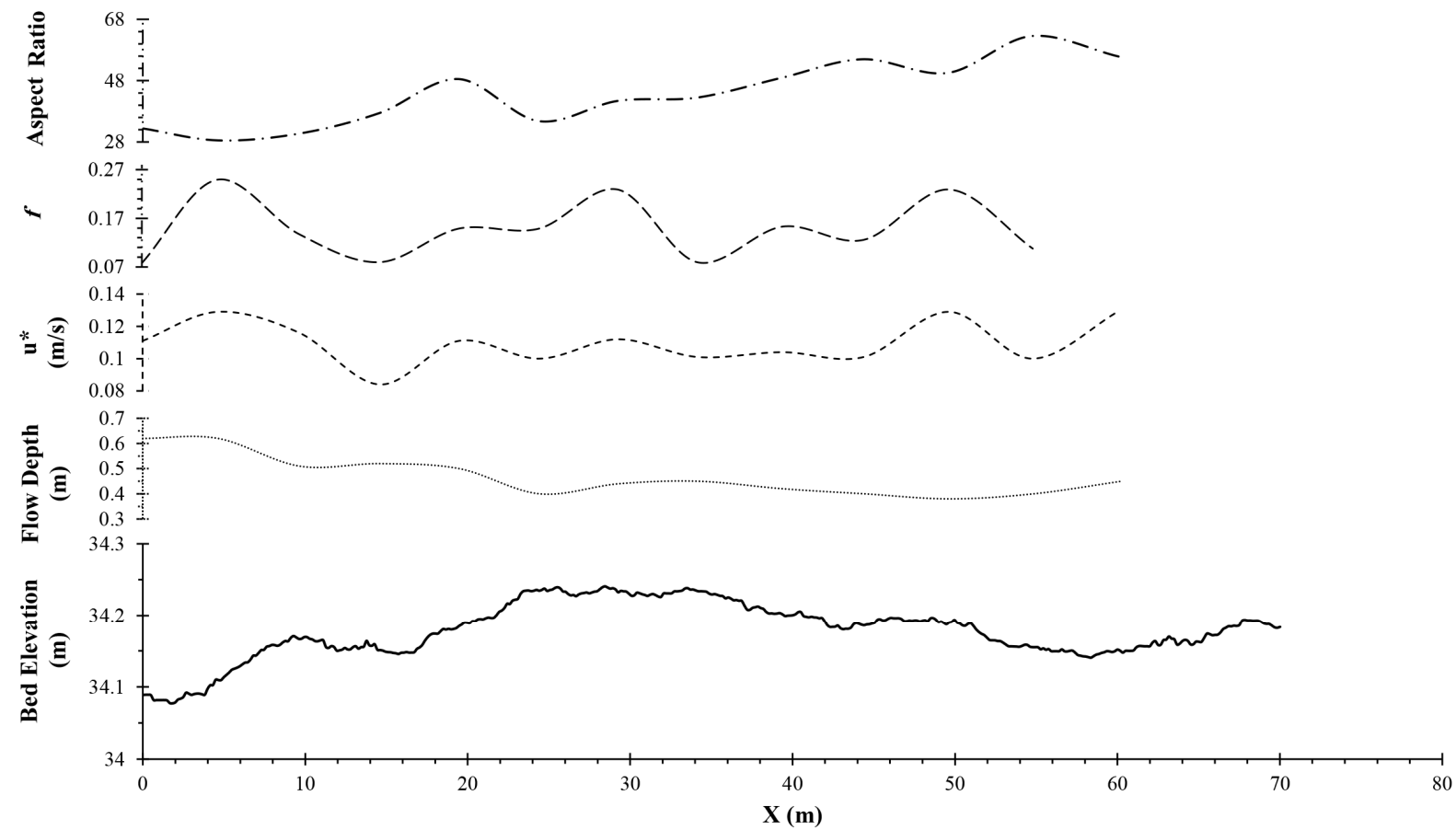

Fig. 13. Distribution of aspect ratio with friction factor along a river reach.

Figure 15 illustrates two riverbed profiles along the central axis of Daroonkola reach with the length of $54 \mathrm{~m}$, the first river reach for two survey periods. It is obvious that with an average discharge of $4.3 \mathrm{~m}^{3} / \mathrm{s}$, there is an erosion volume (per unit width across the river) of $5395.5 \mathrm{~m}^{2}$ during a period of 80 days for this river reach. Since the river has the high flow in March and April, therefore, the increased sediment transport leads to generation of bedforms (Figure 15). Accordingly, the first hypothesis is rejected and probability of occurring such a flood with average depth of much more than $0.44 \mathrm{~m}$ near to $3 \mathrm{~m}$ to create measured bedforms in this study is zero. However, regarding the second hypothesis as mentioned above, van Rijn's method is applied to the channel with the particle size ranges from $490 \mu \mathrm{m}$ to $3600 \mu \mathrm{m}$, calling the modification of the van Rijn's method in order to apply it in the gravel-bed rivers. The results reveal that the modification of this method can be applied to evaluate bedforms dimensions accurately. However, its application in river reaches with small bedforms (approximately flatbed) and $\mathrm{T}>25$ is more justifiable. 

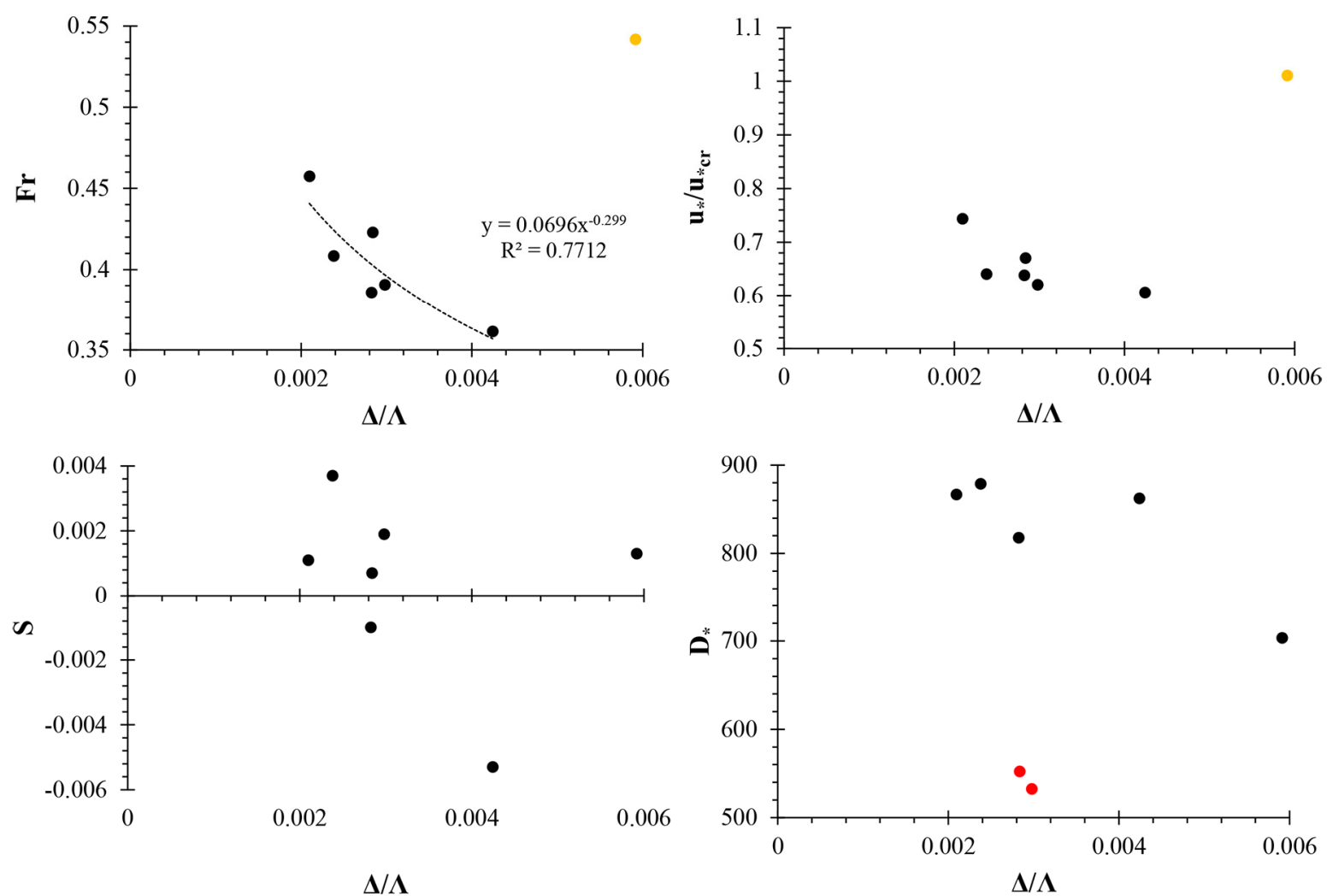

$\Delta / \Lambda$

$\Delta / \Lambda$

Fig. 14. The effects of different parameters on bedform steepness.

\section{Longitudinal Profile Of Riverbed}

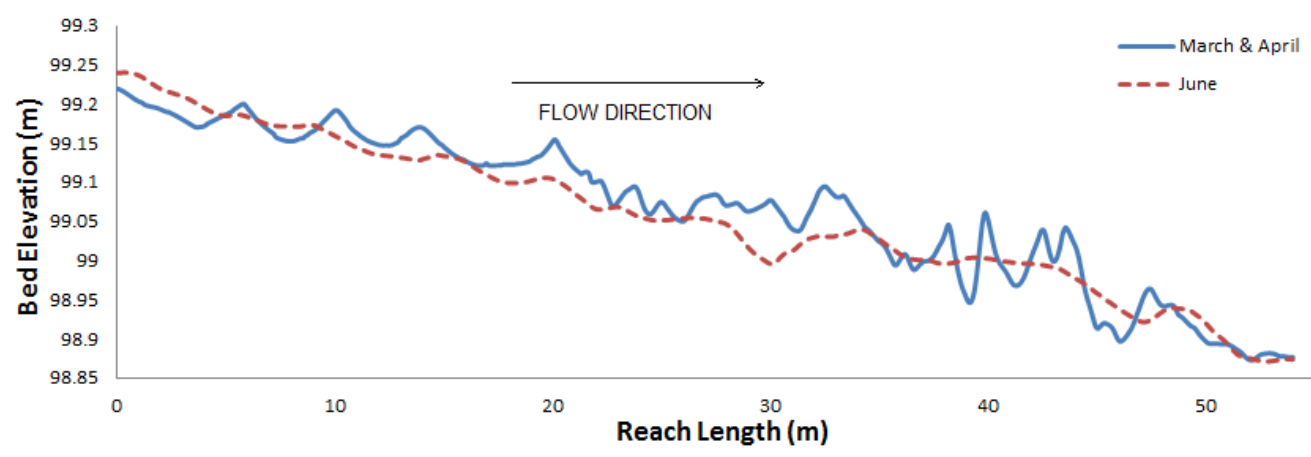

Fig. 15. Longitudinal profile of riverbed during two survey periods.

\section{CONCLUSIONS}

Using the collected data from 4 gravel-bed river reaches with a total length of $356 \mathrm{~m}$, it is found that application of developed equations for sand-bed streams can be modified to apply to an unspecific bedforms of gravel-bed rivers. The modifications were done by using the double-averaged method to estimate mean velocity and mean shear velocity to evaluate the friction factor. Results showed that application of doubleaveraged method is justifiable for an unspecific bedform with reasonable confident limit in river engineering studies.

Based on the observations of the deformation of riverbed during a period of 80 days, it was found that the mechanism of degenerating bedforms remained the same for higher discharges. However, for a specific discharge of $4.3 \mathrm{~m}^{3} / \mathrm{s}$ with the flow depth of $0.3 \mathrm{~m}$ and average velocity of $0.7 \mathrm{~m} / \mathrm{s}$, only small particles (sand) got moved to generate gravel-bedforms.
Neglecting the effect of form friction even in small bedforms (flatbed) may considerably change the estimation of total friction factor, result in unrealistic evaluation as the input of river engineering models.

Most of experimental studies in flumes are conducted with small aspect ratio $(W / h<6)$ and the flume results may not be extended to natural rivers. This reveals the necessity to carry out research in the field for different range of aspect ratios. This study showed that interaction of aspect ratio and bedform plays a significant role in the variation in friction factor for a gravelbed river, calling for more attention to this part of research in gravel-bed rivers. The results of present study does not support from a clear relationship between aspect ratio and friction factor due to very complex interaction among the controlling variables of friction factor. 


\section{REFERENCES}

Afzalimehr, H., 2010. Effect of flow non-uniformity on velocity and turbulence intensities in flow over a cobble-bed. Journal of Hydrological Processes, 24, 331-341.

Afzalimehr, H., Anctil, F., 2000. Accelerating shear velocity in gravel bed channels. Hydrological Sciences Journal, 45, 113-124.

Afzalimehr, H., Rennie, C.D., 2009. Determination of bed shear stress using boundary layer parameters in a gravel-bed river. Hydrological Sciences Journal, 54, 147-159.

Bennett, S.J., Best, J.L., 1995. Mean flow and turbulence structure over fixed, two-dimensional dunes: Implications for sediment transport and bedform stability. Sedimentology, 42, 491-513.

Carling, P.A., 1999. Subaqueous gravel dunes. Journal of Sedimentary Research, 69, 534-545.

Carling, P.A., Richardson, K., Ikeda, H., 2005. A flume experiment on the development of subaqueous fine gravel dunes from a lower stage plane bed. Journal of Geophysical research: Earth Surface, 110, F04S05. DOI: 10.1029/2004JF000205.

Dey, S., 2014. Fluvial Hydrodynamics: Hydrodynamic and Sediment Transport Phenomena. Springer-Verlag. Berlin.

Fazlollahi, A., Afzalimehr, H., Sui, J., 2015a. Impacts of pool and vegetated banks on turbulent flow characteristics. Canadian Journal of Civil Engineering, 42, 12, 979-986. DOI: 10.1139/cjce-0172.

Fazlollahi, A., Afzalimehr, H., Sui, J., 2015b. Effect of slope angle of an artificial pool on distributions of turbulence. International Journal of Sediment Research, 30, 93-99.

Formann, H., Habersack, H.M., Schober, S.T., 2007. Morphodynamics river processes and techniques for assessment of channel evolution in Alpine gravel bed rivers. Geomorphology, 90, 340-355.

Garcia, M., 2008. Sedimentation Engineering: Processes, Measurements, Modeling and Practice, American Society of Civil Engineers.

Julien, P.Y., 1992. Study of bedform geometry in large rivers. Delft Hydraulics, Colorado State University.

Julien, P.Y., 2010. Erosion and Sedimentation. $2^{\text {nd }}$ edition. Cambridge University Press, Cambridge, UK, 371 p.

Julien, P.Y., Klaassen, G.J., 1995. Sand-dune geometry of large rivers during floods. Journal of Hydraulic Engineering ASCE, 121, 657-663.

Keylock, C., Singh, A., Foufoula-Georgiou, E., 2014. The complexity of gravel-bed river topography examined with gradual wavelet reconstruction. Journal of Geophysical Research, 119. DOI: 10.1002/2013JF002999.

Kironoto, B.A., Graf, W.H., 1994. Turbulence characteristics in rough non-uniform open channel flow. Proceeding of the Institution of Civil Engineers, Water and Maritime Engineering, 112, 333-344.

Liedermann, M., Gmeiner, P., Tritthart, M., Glas, M., Habersack, H., 2014. Occurrence and characterization of bedforms at the Danube to the east of Vienna. In: Proceedings of the International Conference on Fluvial Hydraulics, RIVER FLOW. CRC Press/Balkema, pp. 1075-1080.
MacVicar, B.J., Rennie, C.D., 2012. Flow and turbulence redistribution in a straight artificial pool. Water Resources Research, 48, Wo2503. DOI: 10.1029/2010wr009374.

MacVicar, B.J., Roy, A.G., 2007. Hydrodynamics of a forced riffle pool in a gravel bed river: 1 . Mean velocity and turbulence intensity. Water Resources Research, 43, W12401. DOI: $10.1029 / 2006$ WR005272.

Milan, D.J., 2012. Geomorphic impact and system recovery following an extreme flood in an upland stream: Thinhope, northern England, UK. Journal of Geomorphology, 138, 319-328.

Motamedi, A., Afzalimehr, H., Singh, V.P., Dufresne, L., 2014. An experimental study on the influence of dune dimensions of flow separation. Journal of Hydrologic Engineering ASCE, 19, 78-86.

Nasiri Dehsorkhi, E., Afzalimehr, H., Singh, V.J., 2010. Effect of bedforms and vegetated banks on velocity distributions and turbulent flow structure. Journal of Hydrologic Engineering ASCE, 16, 495-507.

Nikora, V., Goring, D., McEwan, I., Griffiths, G., 2001. Spatially averaged open-channel flow over rough bed. Journal of Hydraulic Engineering, 127, 123-133.

Raslan, Y., 1991. Geometrical properties of dunes. M.Sc. Thesis, Department of civil engineering, Colorado State University, Fort Collins, USA.

Schlichting, H., Geresten, K., 2000. Boundary-Layer Theory. Springer-Verlag, Berlin.

Singh, A., Foufoula-Georgiou, E., Porte-Agel, F., Wilcock, P.R., 2012. Coupled dynamics of the co-evolution of gravel bed topography, flow turbulence and sediment transport in an experimental channel. Journal of Geophysical Research, 117, F04016. DOI: 10.1029/2011JF002323.

Terms, A.P.P., 1986. Dimensies van bed dingvormen onder permanente stroming som standigheden bij hoog sediment transport. Verslag onderzoek, M 2130/Q232. (In Dutch.)

van der Mark, C.F., Blom, A., 2007. A new and widely applicable bedform tracking tool. University of Twente.

van der Mark, C.F., Blom, A., Hulscher, S.J.M.H., 2008. Quantification of variability in bedform geometry. Journal of Geophysical Research. Pt. F: Earth surface, 113 (F03020).

van Rijn, L.C., 1984. Sediment transport, part 3: Bedforms and alluvial roughness. Journal of Hydraulic Engineering ASCE, 110, 1733-1754.

van Rijn, L.C., 1993. Principles of Sediment Transport in Rivers, Estuaries and Coastal Seas. Aqua Publications, Amsterdam.

Vanoni, V.A., Brooks, N.H., 1957. Laboratory studies of roughness and suspended load of alluvial streams. Sedimentation Laboratory Report No. E66, California Institute of Technology, Pasadena, CA, $121 \mathrm{p}$.

Wolman, M.G., 1954. A method of sampling coarse river-bed material. Journal of American Geophysics Union, 35, 951-956.

Yalin, M.S., 1992. River Mechanics. Pergamon Press Ltd, Oxford.

Received 25 April 2016 Accepted 11 January 2017 